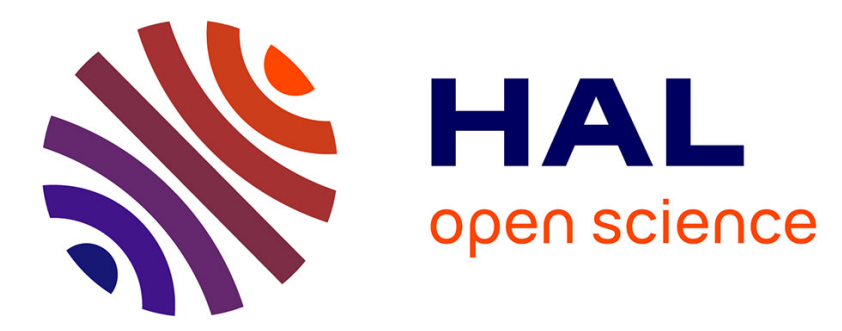

\title{
Insurance and forest rotation decisions under storm risk
}

Patrice Loisel, Marielle Brunette, Stéphane Couture

\section{To cite this version:}

Patrice Loisel, Marielle Brunette, Stéphane Couture. Insurance and forest rotation decisions under storm risk. World Congress of Environmental and Resource Economists, Jun 2018, Göteborg, Sweden. 2018. hal-02785140

\section{HAL Id: hal-02785140 \\ https://hal.inrae.fr/hal-02785140}

Submitted on 4 Jun 2020

HAL is a multi-disciplinary open access archive for the deposit and dissemination of scientific research documents, whether they are published or not. The documents may come from teaching and research institutions in France or abroad, or from public or private research centers.
L'archive ouverte pluridisciplinaire HAL, est destinée au dépôt et à la diffusion de documents scientifiques de niveau recherche, publiés ou non, émanant des établissements d'enseignement et de recherche français ou étrangers, des laboratoires publics ou privés. 


\title{
Insurance and forest rotation decisions under storm risk
}

\author{
Patrice Loisel, Marielle Brunette ${ }^{\dagger}$ Stéphane Couture ${ }^{\ddagger}$
}

January 31,2018

\begin{abstract}
Forests are often threatened by storms; and such a threat is likely to increase due to climate change. Indeed, climate change is expected to increase the frequency and intensity of extreme events such as intensive storms. For forest owners, adaptation to climate change will require major adjustments in forest management practices. Then, forest owners will have to take these increasing risks into account through risk-sharing (insurance) and risk-reducing strategies (reduction of rotation length). In this paper, we propose to jointly analyze the forest owner's insurance decision and the rotation age under storm risk. We extend the Faustmann optimal rotation model under risk, first, considering the forest owner's preferences towards risk, and second, integrating the decision of insurance. With this analytical model, we show that unless the forest owner's discount rate and the insurer's discount rate are sufficiently unequal, it is not optimal for the forest owner to adopt insurance. We prove that the rotation length increases as the insurance premium increases, i.e. substitution between the two coverage mechanisms. Finally, we discuss the potential implications of government policy on the insurance scheme.
\end{abstract}

Keywords: Faustmann Value, insurance, risk-sharing, storm risk, rotation length, subsidy

JEL: D81, G22, Q23.

\footnotetext{
*MISTEA, INRA, Montpellier SupAgro, Univ Montpellier, Montpellier, France. patrice.loisel@inra.fr

${ }^{\dagger}$ BETA, Université de Lorraine, INRA, AgroParisTech, 54000, Nancy, France; Climate Economics Chair, Paris, France. marielle.brunette@inra.fr

${ }^{\ddagger}$ MIAT, INRA, University of Toulouse, 31326 Castanet-Tolosan, France. stephane.couture@inra.fr
} 


\section{Introduction}

Natural hazards represent serious threat for forest ecosystems. In particular, storms are the more damageable event for European forest since they are responsible for more than 50\% of the European forest damage over the period 1950-2000 (Schelhaas et al., 2003). In the same vein, Gardiner et al. (2013) reported 130 storms over the last sixty years in Europe, i.e., an average of two storms per year. Since 1999, three main storms generate important damages in European forests, and in particular in France. Lothar and Martin in 1999 induced 6 billions Euros of damage for the whole France, while Klaus in 2009 generated an average cost of 1.5 billion Euros in the South-western part of France (Rakotoarison and Loisel, 2017).

The occurrence of storm generates various type of losses both for forest owners and society: loss of marketability, costs of storage and restoration, losses in other income such as hunting leases or losses of carbon sequestration and amenities (Brunette et al., 2015). Climate change is expected to increase the frequency and intensity of disturbances (Flannigan et al., 2000; Fuhrer et al., 2006) and in particular those of storm (Haarsma et al., 2013).

To face such events, forest owners may adopt classical risk-sharing strategy like insurance contract. Various European countries propose insurance contract against storm and/or fire like for example France, Germany, Slovakia, Spain, etc (Brunette et al., 2015). Such a contract allows the forest owner to transfer the risk to the insurer. In exchange of the payment of a premium, the owner perceives an indemnity in case of storm occurrence. Another option available for the forest owner to face the increasing risk of storm is to adapt the silvicultural management. A classical risk-reducing strategy in forestry is to reduce the rotation length (Lindner et al., 2000; Spittelhouse and Stewart, 2003), i.e., the time from the establishment of the stand to its final felling. Such a strategy allows diminishing both the time of exposure to natural event and the vulnerability of trees due to ageing (Bréda and Pfeiffer, 2014).

Traditionally, in the literature, decisions related to insurance and rotation length have been analyzed separately. The forest owner's insurance decision has been studied in relation to the disincentive role played by public help implemented by government after the occurrence of a disaster (Brunette and Couture, 2008; Brunette et al., 2013). A part of the literature also deals with the determination of the optimal insurance premium through an actuarial approach (Holecy and Hanewinkel, 2006; Pinheiro 
and Ribeiro, 2013; Brunette et al., 2015). One of the main conclusion is that, in order to provide relevant forest insurance premium, the insured forest area should increase, leading Brunette et al. (2015) to suggest an European forest insurance scheme. In this forest insurance literature, the analysis of insurance decision under risk is generally realized from a static point of view whereas the problem of forest management under risk is typically a dynamic sequential decision problem under uncertainty. It is fundamental to consider this temporal and sequential aspect in the definition of insurance contract because when a risk occurs, the loss covered by insurance strongly depends on the optimal rotation decision of the forest owner. To our knowledge, in this literature, the insurer's behavior is never modeled and integrated into the analysis.

The optimal rotation length is the common research question in forest economics tackled through the classical Faustmann approach (Faustmann, 1849). This approach allows the evaluation of the Land Expectation Value (LEV) over an infinite sequence of rotation. Consequently, the optimal harvesting age in a Faustmann framework has been addressed a lot in the literature (Naslund, 1969; Schreuder, 1971; Kao and Brodie, 1980; Roise, 1986; Haight et al., 1992; Jacobsen et al., 2016). However, originally, this approach is deterministic. Reed (1984) was the first to introduce risk in the Faustmann framework. He showed that a potential total destruction due to a fire risk acts as an increase in the discount rate. Such a framework has then been applied to different risks, and recently to disease (Macpherson et al., 2016). To our knowledge, few studies focused on the impact of storm risk on optimal rotation length in a Faustmann framework. Haight et al. (1995) studied the impact of storm on the expected present value. They showed that age-dependent damage risk and stocking reduction caused by tree mortality have the greatest impact on the relationship between the expected present value and rotation age. Loisel (2014) showed that considering storm risk leads to earlier optimal thinning than without risk. Recently, Rakotoarison and Loisel (2017) jointly analyzed storm risk and price risk in a Faustmann model. They propose simulations of their theoretical model for European beech stand in Northwestern France. The simulations indicate that the storm risk reduces the optimal rotation length, limits the number of thinning and increases economic loss (but less than price variation).

In this context, it seems that insurance decision and decision related to optimal rotation length have never been studied jointly. Thus, we propose to tackle the question of the impact of insurance decision on the optimal rotation length. For that purpose, we extend the Faustmann optimal rotation model under risk by considering the decision of insurance. Our paper has two additional contributions. First, 
linked to the rotation and insurance model of the forest owner, we propose to model the microeconomic behavior of the insurer in order to define the components of the insurance contract. Second, in order to analyze insurance decision, we integrate into the model the forest owner's preferences towards risk associated to an expected utility maximization criteria. Such a criteria allows to explicitly consider the forest owner's preferences towards risk, i.e., neutrality, risk aversion or risk loving. Indeed, previous works have proved that forest owners are risk averse on average (Musshof and Maart-Noelck, 2014; Sauter et al., 2016; Brunette et al., 2017). In addition, the impact of risk aversion on optimal rotation length has been proved in various modeling approaches, like mean-variance approach (Ollikainen, 1993; Gong and Lofgren, 2005; Caulfield, 1988; Taylor and Forston, 1991; Valsta, 1992), Wicksellian single rotation framework (Alvarez and Koskela, 2006), heuristic method (Kangas, 1994; Pukkala and Kangas, 1996) or expected utility maximization model (Gong, 1998). A majority of papers obtained that risk aversion tends to shorten the optimal rotation length (Caulfield, 1988; Taylor and Forston, 1991; Alvarez and Koskela, 2006; Gong, 1998) while (Valsta, 1992) found the opposite result. Moreover, one of the main factors explaining the individual's insurance decision is risk aversion. A risk-averse individual is willing to transfer a part of risk to a third party even if it is costly. It is fundamental to consider the risk preferences of the forest owner when analyzing the insurance decision. However, to our knowledge, the forest owner's preferences towards risk have never been considered in a Faustmann modeling.

The rest of the paper is structured as follows. Section 2 presents the model. Section 3 develops the maximization program of the forest owner and the insurer. Finally, Section 4 discusses the results while Section 5 provides the conclusion.

\section{Modeling the risk and the insurance contract}

\subsection{Modeling storm risk and its impact on the stand}

We suppose that the occurrence of storm follows a Poisson process, i.e., that storms occur independently of one another, and randomly in time. This is a classical assumption in the literature to model both storm and fire (Reed, 1984; Yin and Newman, 1996; Fina et al., 2001; Ohlson et al., 2006; Armstrong et al., 2007; Jacobsen, 2007; Loisel, 2011). Thus the distribution of the times between successive storms is an exponential with mean $1 / \lambda: F(x)=1-e^{-\lambda x}$ where $\lambda$ is the expected number of storms per unit of 
time. The severity of the storm is given by the random variable $\mathcal{A}$. Let $\tau$ be the period of time between the beginning of the stand and, either the storm occurrence or the final harvesting. The storm risk is then described by the couple of random variables $(\tau, \mathcal{A})$.

Unlike other types of risk such as fire, the impacts of storm are age-dependent and are low on young stands. Following Schmidt et al. (2010), we assume that, for a tree-height $H$ less equal than $H_{L}$, there is no damage. The height $H_{L}$ is reached at a time $t_{L}$, the time $t_{L}$ explicitly depends on the height limit $H_{L}$ and can be deduced using the time dependent function $H: H\left(t_{L}\right)=H_{L}$. Therefore, in case of storm occurrence before $t_{L}$, the storm has no impact. At the opposite, in case of storm occurrence after $t_{L}$, the proportion of damaged trees $\theta_{t}$ depends on the severity of the storm $\mathcal{A}$ and the characteristics of the stand when the storm occurs (tree height, tree diameter which are age-dependent), hence the proportion of damaged trees is age-dependent. Let $\alpha(t)$ represents the expectation of the proportion of survival trees $1-\theta_{t}$.

\subsection{The sequence of events}

Without risk, the forest stand grows from $t=0$ (plantation or regeneration) to $T$, with $T$ the harvesting age. The storm risk modifies the sequence of events as follows:

- If a storm occurs before $t_{L}$, there is no impact and the stand growth continues.

- If a storm occurs after $t_{L}$ but before $T$, the proportion of damaged trees is $\theta$, a clear-cutting and a regeneration (or plantation) of the stand is realized.

- If no storm occurs before $T$, a clear-cutting and a regeneration (or plantation) of the stand is realized at time $T$.

Let $\tau$ be the spending time between the beginning of the stand and the first event after $t_{L}$, i.e., storm occurrence or harvesting at time $T$. The distribution of the random variable $\tau$ is defined for $t_{L}<t \leq T$ as $F_{\tau}(t)=F\left(t-t_{L}\right)=1-e^{-\lambda\left(t-t_{L}\right)}$.

Let $L(\theta, \tau)$ the loss following a storm occurring at time $\tau$ for a proportion of damages trees $\theta$. This loss represents the unexploitability of damaged trees: $L(\theta, \tau)=\theta V(\tau)$ where $V(\tau)$ is the potential final (without risk) income at time $\tau$. 


\subsection{Modeling the insurance contract}

An insurance contract is defined as a couple (premium, indemnity), so that we described these two variables in our model.

The contract is characterized by a upper premium $\overline{\mathcal{P}}$ by unit of time (directly linked to the actualization of future losses, see next section) for the full coverage of the damage $L(\theta, \tau)$, i.e., damage associated to a storm occurring at time $\tau$. The forest owner chooses a premium $\mathcal{P}$ which is a percentage $\xi$ of $\overline{\mathcal{P}}$, so that $\mathcal{P}=\xi \overline{\mathcal{P}}$. If the forest owner chooses $\xi=1$ then, s/he is fully insured in case of storm occurrence, in the sense that the the damage is fully covered by insurer. At the opposite, $\xi=0$ means no insurance. All the other cases, for $0<\xi<1$, correspond to partial insurance, where only a part of the damage is covered by insurer, the other part being borne by the forest owner. Then, $\xi$ represents the forest owner's degree of insurance coverage.

The indemnity perceives by the forest owner, in case of a storm occurring at time $\tau$, is then $\mathcal{I}\left(\theta_{\tau}, \tau\right)=$ $\xi L\left(\theta_{\tau}, \tau\right)$. The indemnity corresponds to the percentage $\xi$ of the loss with, as defined above, $0 \leq \xi \leq 1$.

\section{The programs of the involved stakeholders}

The forest owner's decision variables are the harvesting age $T$ and the percentage $\xi$ as regard to insurance decision, while the insurer chooses the upper premium $\overline{\mathcal{P}}$. Let's turn to the analysis of each individual's maximization program.

\subsection{The forest owner's program}

In this section, we determine the forest owner's decision related to the rotation length, assuming a given level of insurance. The forest owner is characterized by an utility function $u$ with $u^{\prime}()>$. and $u^{\prime \prime}()<$.0 to represent risk aversion. The forest owner is assumed to maximize the utility of the net economic return from silvicultural activity. This utility of the net economic return $\mathcal{Y}$, actualized at 
storm occurrence time $\tau$ or logging time $T$, writes as follows:

$$
\mathcal{Y}= \begin{cases}P_{0}(\underline{t}, \tau)+\mathcal{H}_{\delta}(\underline{t}, \tau)+u\left(V_{1}\left(\theta_{\tau}, \tau\right)+\mathcal{I}\left(\theta_{\tau}, \tau\right)-c_{1}-C_{n}\left(\theta_{\tau}, \tau\right)\right) & \text { if } t_{L}<\tau<T \\ P_{0}(\underline{t}, T)+\mathcal{H}_{\delta}(\underline{t}, T)+u\left(V(T)-c_{1}\right) & \text { if } \tau=T\end{cases}
$$

with:

- $P_{0}(\underline{t}, t)=\int_{0}^{\underline{t}} u(-\mathcal{P}) e^{\delta(t-s)} d s$, the insurance premium paid by the forest owner between the initial time and time $\underline{t}$, actualized at time $t$.

- $H_{\delta}(\underline{t}, t)=\int_{\underline{t}}^{t} u(h-\mathcal{P}) e^{\delta(t-s)} d s$, the thinning incomes between time $\underline{t}$ and time $t$ actualized at time $\tau$.

- $V_{1}\left(\theta_{\tau}, \tau\right)=\left(1-\theta_{\tau}\right) V(\tau)$, the final income in case of storm occurring at time $\tau$.

- $c_{1}$, the regeneration (or plantation) cost.

- $C_{n}\left(\theta_{\tau}, \tau\right)$ the clearing costs for a storm occurring at time $\tau$.

We deduce the following expression for the Faustmann value $J_{F}$ (see Appendix A):

$$
J_{F}=\frac{E\left[e^{-\delta \tau} \mathcal{Y}\right]}{1-E\left[e^{-\delta \tau}\right]}=\frac{1}{b(T)}\left[\frac{a_{0}(T) u(-\mathcal{P})+a_{1}(T) u(h-\mathcal{P})}{\delta}+W_{F}(0, T)\right]
$$

where $a_{0}(T)=e^{(\delta+\lambda) T-\lambda t_{L}}\left(1-e^{-\delta \underline{t}}\right), a_{1}(T)=e^{(\delta+\lambda) T-\lambda t_{L}-\delta \underline{t}}-\frac{\lambda e^{(\delta+\lambda)\left(T-t_{L}\right)}+\delta}{\delta+\lambda}, b(T)=a_{0}(T)+$ $a_{1}(T)$ and $W_{F}(0, T)$ is a modified income such that:

$$
W_{F}(0, T)=\lambda \int_{t_{L}}^{T} E\left[u\left(V_{1}(\theta, \tau)+\mathcal{I}\left(\theta_{\tau}, \tau\right)-c_{1}-C_{n}\left(\theta_{\tau}, \tau\right)\right)\right] e^{(\delta+\lambda)(T-\tau)} d \tau+u\left(V(0, T)-c_{1}\right)
$$

This modified income is composed of two parts. The first part is the integral, with respect to $\tau$, of a reduced final income minus the clearing costs in case of a storm at time $\tau<T$. The second part represents the final income in case of no storm before cutting age $T$.

This Faustmann value, obtained with storm risk and insurance, differs from the Faustmann value without risk, in several ways. First, the discount rate $\delta$ is replaced by the addition of the discount rate and expected number of storms $\delta+\lambda$ (as previously noticed by Reed (1984) without thinning and Price 
(2011) with thinning). Second, the utility of the final income $W_{0}(0, T)=u\left(V(T)-c_{1}\right)$ is replaced by $W_{F}(0, T)$. More precisely, an integral relative to the final cutting minus clearing costs in case of a storm before the cutting age $T$ is added.

The maximum of the Faustmann value is obtained by solving:

$$
\max _{T} J_{F}=\frac{1}{b(T)}\left[\frac{a_{0}(T) u(-\mathcal{P})+a_{1}(T) u(h-\mathcal{P})}{\delta}+W_{F}(0, T)\right]
$$

We consider comparative statics relative to the maximization with respect to the rotation period $T$. We obtain the following results (proof in Appendix B):

Proposition 1 For a risk averse forest owner with differentiated loss and gain risk aversion function $\left(u(x)=u_{+} x_{+}-u_{-} x_{-}\right.$with $\left.u_{+} \leq 1 \leq u_{-}\right)$, the optimal cutting age $T$ satisfies: $T_{\mathcal{P}}>0$ and $T$ increases as the degree of insurance coverage $\xi$ increases.

This result indicates that the risk-sharing strategy and the risk-reducing one are substitutes for the forest owner. Indeed, as the insurance coverage increases, then the forest owner reduces the riskreducing strategy, leading to an increase in the rotation length. This result is in line with the standard result of Ehrlich and Becker (1972) indicating that insurance and self-insurance are substitutes. Here, the reduction of rotation length may be associated to a self-insurance activity, in the sense that it reduces the damage in case of storm occurrence.

\subsection{The insurer's program}

We assume that the insurer's discount rate is different from the owner's one and is noted $\delta_{A} . b$ calculated with discount rate $\delta$ is replaced by the corresponding $b_{A}$ with $\delta_{A}$. The Faustmann value $J_{A}$ is:

$$
\begin{array}{rlr}
J_{A} & =\xi \frac{\overline{\mathcal{P}}}{\delta_{A}}-\left(1+l_{f}\right)(1+m) \frac{E\left[e^{-\delta \tau} \mathcal{I}\left(\theta_{\tau}, \tau\right)\right]}{1-E\left[e^{-\delta \tau}\right]} & \text { (expectation with respect to } \theta \text { and } \tau) \\
& \left.=\xi \frac{\overline{\mathcal{P}}}{\delta_{A}}-\lambda\left(1+l_{f}\right)(1+m) \frac{\int_{t_{L}}^{T} E\left[\mathcal{I}\left(\theta_{\tau}, \tau\right)\right] e^{\left(\lambda+\delta_{A}\right)(T-\tau)} d \tau}{b_{A}(T)} \quad \text { (expectation with respect to } \theta\right)
\end{array}
$$

where $E\left[\mathcal{I}\left(\theta_{\tau}, \tau\right)\right]=E\left[\xi L\left(\theta_{\tau}, \tau\right)\right]=\xi E\left[L\left(\theta_{\tau}, \tau\right)\right]$ is the expected insurance income, $l_{f}$ is the loading factor and $m$ the security coefficient. 
The objective of the insurer is to generate benefits from the insurance activity. In order to have benefit, the insurer must choose $\overline{\mathcal{P}}>\left(1+l_{f}\right)(1+m) \mathcal{P}_{0}(T)$ where $\mathcal{P}_{0}(T)$ is the Faustmann value associated to the future losses multiplied by the discount rate $\delta_{A}$ for the cutting age $T$ :

$$
\mathcal{P}_{0}(T)=\delta_{A} \frac{E\left[e^{-\delta \tau} L\left(\theta_{\tau}, \tau\right)\right]}{1-E\left[e^{-\delta \tau}\right]}=\lambda_{\frac{\delta_{A}}{b_{A}(T)}} \int_{t_{L}}^{T} E\left[L\left(\theta_{\tau}, \tau\right)\right] e^{\left(\lambda+\delta_{A}\right)(T-\tau)} d \tau
$$

This constraint depends on the cutting age $T$ chosen by the forest owners. $\overline{\mathcal{P}}$ may not depend on the cutting age $T$, while in the forest owner's program, $T$ depends on $\overline{\mathcal{P}}$. In order to ensure a level $m$ for its benefit, the insurer has to evaluate the optimal harvesting age from the forest owner's point of view.

$\mathcal{P}_{0}$ is decreasing with respect to cutting age $T$. Assuming that the forest owner decides of a cutting age lower than in the case without risk $T_{0}$, then the condition becomes: $\overline{\mathcal{P}}>\left(1+l_{f}\right)(1+m) \mathcal{P}_{0}\left(T_{0}\right)$. The insurer thus has all the information necessary to determine the insurance contract, and to assess the insurance premium and the indemnity.

\subsection{Analysis of the optimal insurance decision}

In this section, we determine the optimal insurance decision considering that the optimal rotation length is given. We assume $\overline{\mathcal{P}}=\left(1+l_{f}\right)(1+m) \mathcal{P}_{0}(T)$ where $T$ is assumed known (and then, not necessarily optimal). The Faustmann value becomes:

$$
\begin{array}{r}
J_{F}=\frac{a_{0}(T) u(-\mathcal{P})+a_{1}(T) u(h-\mathcal{P})}{\delta b(T)} \\
+\frac{\overline{\mathcal{P}}}{\left(1+l_{f}\right)(1+m) \delta_{A}} \frac{b_{A}(T)}{b(T)} \frac{\int_{t_{L}}^{T} E\left[u\left(V_{1}(\theta, \tau)+\mathcal{I}\left(\theta_{\tau}, \tau\right)-c_{1}-C_{n}\left(\theta_{\tau}, \tau\right)\right] e^{(\lambda+\delta)(T-\tau)} d \tau\right.}{\int_{t_{L}}^{T} E\left[L\left(\theta_{\tau}, \tau\right)\right] e^{\left(\lambda+\delta_{A}\right)(T-\tau)} d \tau} \\
+\frac{u\left(V(T)-c_{1}\right)}{b(T)}
\end{array}
$$

We consider the derivative of the Faustmann Value $J_{F}$ with respect to insurance premium $\mathcal{P}$. We obtain the following results (proof in Appendix C):

Proposition 2 (i) If the discount rates of the forest owner and the insurer are equal $\left(\delta_{A}=\delta\right)$ then for harvesting age $T$, premium $\mathcal{P}_{*}(T)=0$ is optimal.

(ii) If the forest owner's discount rate and the insurer's discount rate are sufficiently unequal then for 
harvesting age $T$, premium $\mathcal{P}_{*}(T)>0$ is optimal.

This proposition indicates that, in some cases, it may be optimal for a risk averse forest owner to not adopt insurance. This result is not surprising since the premium proposed by the insurer, $\overline{\mathcal{P}}$, corresponds to a loaded (or unfair) premium. Consequently, the forest owner may consider that the insurance premium is too high and may prefer to not insure despite risk aversion. A way to reduce the insurance premium may be that the public authority subsidizes the premium.

\subsection{Insurance subsidy}

In the literature, the subsidy for the forest insurance premium has already been mentioned in Brunette et al. (2013). They obtained theoretically that, when the government provides a subsidy to the forest owner for her/his insurance premium, then the forest owner should increase the insurance demand. However, they do not validate this result with the empirical part of the paper. In this article, we adopt another idea which is that, rather than to subsidy the forest owner directly, the government subsidies the insurer.

Indeed, we consider that the government gives a percentage $\gamma$ of the indemnity to insurer. Consequently, it is as a coinsurance contract where a part $\gamma$ of the damage is borne by the government while $1-\gamma$ is borne by the insurer (and/or the forest owner in case of partial insurance demand). The risk supported by the insurer is lower, the indemnity paid by the insurer in case of storm occurrence also and the insurance premium too, hence:

$$
\mathcal{P}_{0}(T)=(1-\gamma) \frac{\lambda \delta_{A}}{b_{A}(T)} \int_{t_{L}}^{T} E\left[L\left(\theta_{\tau}, \tau\right)\right] e^{\left(\lambda+\delta_{A}\right)(T-\tau)} d \tau
$$

We consider the derivative of the Faustmann Value $J_{F}$ with respect to insurance premium $\mathcal{P}$ when $\delta_{A}=\delta$. We obtain the following results (proof in Appendix D):

Proposition 3 If the discount rates of the forest owner and the insurer are equal $\left(\delta_{A}=\delta\right)$, and if the government gives a percentage $\gamma$ such that $0<\underline{\gamma}(\delta)<\gamma<\bar{\gamma}(\delta)<1$ of the indemnity to the insurer then an insurance premium $\mathcal{P}_{*}(T)>0$ may be optimal.

By subsidizing the insurer, the government increases the attractiveness of insurance for the forest 
owner.

\section{Discussion}

As underlined by Brunette et al. (2015), the adoption of a forest insurance contract is still an exception in Europe. For example, in France, only approximately $4 \%$ of the French private forests are insured representing 400,000 ha of private forests. Similar observations are obtained for Spain, Germany or Slovakia (Brunette et al., 2015). The literature explores different potential explanations for this low level of insurance, among which the existence of public program to financially help the forest owners after the occurrence of storms. In this context, Brunette and Couture (2008) and Brunette et al. (2013) showed that a public help reduces the forest owners' insurance demand, but that this negative effect is lower when the help is contingent to insurance adoption rather than fixed (i.e., independent from any insurance contract adoption). In this paper, we provide another potential explanation to the nonadoption of insurance contract by private forest owners, the fact that, in some cases, insurance may be considered as too expensive by the forest owner (see Proposition 2). In addition, as regard to the existing literature, we explore another channel from which the government may participate to the insurance scheme. Indeed, we show that, by subsidizing the insurer, the government encourages the forest owner to adopt insurance contract. Consequently, an horizontal risk sharing between the insurer, the forest owner and the government may be an efficient way to insure storm risk in forest.

\section{Conclusion}

In this paper, we propose to extend the classical Faustmann rotation model under risk by considering the insurance decision. This means that, in addition to the decision related to the rotation length, the forest owner also decides on a degree of insurance coverage. Such a challenge requires to model the insurer's behavior (in order to determine the contract) and to consider the forest owner's preferences towards risk (in order to analyze the insurance decision), two supplementary originalities for this paper. In this framework, our results indicate that the forest owner considers that the risk-sharing strategy (insurance) and the risk-reducing one (reduction of the rotation length) are substitutes. In addition, we show that, in 
some cases, it may be optimal for the forest owner to not adopt insurance. Finally, we conclude that, a way to incite forest owners to adopt insurance contract is to consider that the government subsidizes the insurer.

\section{Acknowledgments}

The UMR BETA is supported by a grant overseen by the French National Research Agency (ANR) as part of the "Investissements d'Avenir" program (ANR-11-LABX-0002-01, Lab of Excellence ARBRE).

\section{References}

L. Alvarez and E. Koskela. Does risk aversion accelerate optimal forest rotation under uncertainty? Journal of Forest Economics, 12:171-184, 2006.

D.P. Armstrong, I. Castro, and R. Griffiths. Using adaptive management to determine requirements of re-introduced populations: the case of the new zealand hihi. Journal of Applied Ecology, 44:953-962, 2007.

N. Bréda and M. Pfeiffer. Vulnerability to forest decline in a context of climate changes: new prospects about an old question in forest ecology. Annals of Forest Science, 71:627-631, 2014.

M. Brunette and S. Couture. Public compensation for windstorm damage reduces incentives for risk management investments. Forest Policy and Economics, 10(7-8):491-499, 2008.

M. Brunette, L. Cabantous, S. Couture, and A. Stenger. The impact of governmental assistance on insurance demand under ambiguity: A theoretical model and an experimental test. Theory and Decision, 75:153-174, 2013.

M. Brunette, J. Holecy, M. Sedliak, J. Tucek, and M. Hanewinkel. An actuarial model of forest insurance against multiple natural hazards in fir (abies alba mill.) stands in slovakia. Forest Policy and Economics, 55:46-57, 2015.

M. Brunette, J. Foncel, and E.N. Kéré. Attitude towards risk and production decision : An empirical analysis on french private forest owners. Environmental Modeling and Assessment, 2017. 
J. Caulfield. A stochastic efficiency approach for determining the economic rotation of a forest stand. Forest Science, 34:441-457, 1988.

I. Ehrlich and G.S. Becker. Market insurance, self-insurance, and self-protection. Journal of Political Economy, 80(4):623-648, 1972.

M. Faustmann. Berechnung des wertes welchen waldboden sowie noch nicht haubare holzbestunde fur die weldwirtschaft besitzen. Allgemeine Forst-und Jagd-Zeitung, 25:441-445, 1849.

M. Fina, G.S. Amacher, and J. Sullivan. Uncertainty, debt, and forest harvesting: Faustmann revisited. Forest Science, 47:188-196, 2001.

M.D. Flannigan, B.J. Stocks, and B.M. Wotton. Climate change and forest fires. $\underline{\text { Science of the Total }}$ Environment, 262:221-229, 2000.

J. Fuhrer, M. Beniston, A. Fischlin, C. Frei, S. Goyette, K. Jasper, and C. Pfister C. Climate risks and their impact on agriculture and forests in switzerland. Climatic Change, 79:79-102, 2006.

B. Gardiner, A. Schuck, M. Schelhaas, C. Orazio, K. Blennow, and B. Nicoll. Living with storm damage to forests. European Forestry Institute, Joensuu, 2013.

P. Gong. Risk preferences and adaptive harvest policies for even-aged stand management. Forest Science, 44(4):496-506, 1998.

P. Gong and K. Lofgren. Impact of risk aversion on optimal rotation age. Umea: Scandinavian WP no666,Swedish University of Agricultural Sciences, 2005.

R.J. Haarsma, W. Hazeleger, C. Severijns, H. de Vries, A. Sterl, R. Bintanja, G.J. van Oldenborgh, and H. van den Brink. More hurricanes to hit western europe due to global warming. Geophysical Research Letters, 40(9):1783-1788, 2013.

R.G. Haight, R.A. Monserud, and J.D. Chew. Optimal harvesting with stand density targets: Managing rocky mountain conifer stands for multiple forest outputs. Forest Science, 38(3):554-574, 1992.

R.G. Haight, W.D. Smith, and T.J. Straka. Hurricanes and the economics of loblolly pine plantations. Forest Science, 41(4):675-688, 1995. 
J. Holecy and M. Hanewinkel. A forest management risk insurance model and its application to coniferous stands in southwest germany. Forest Policy and Economics, 8(2):161-174, 2006.

J.B. Jacobsen. The regeneration decision: a sequential two option approach. Canadian Journal of Forest Research, 37:439-448, 2007.

J.B. Jacobsen, F. Jensen, and B.J. Thorsen. Forest value and optimal rotations in continuous cover forestry. Environmental and Resource Economics, DOI:10.1007/s10640-016-0098-z, 2016.

J. Kangas. Incorporating risk attitude into comparison of reforestation alternatives. Scandinavian Journal of Forest Research, 9:297-304, 1994.

C. Kao and J.D. Brodie. Simultaneous optimization of thinnings and rotation with continuous stocking and entry intervals. Forest Science, Monograph 22, pages 338-346, 1980.

M. Lindner, P. Lasch, and M. Erhard. Alternative forest management strategies under climate change: prospects for gap model applications in risk analyses. Silva Fennica, 34:101-111, 2000.

P. Loisel. Faustmann rotation and population dynamics in the presence of a risk of destructive events. Journal of Forest Economics, 17(3):235-247, 2011.

P. Loisel. Impact of storm risk on faustmann rotation. Forest Policy and Economics, 38:191-198, 2014.

M.F. Macpherson, A.Kleczkowski, J.R. Healey, and N.Hanley. The effects of disease on optimal forest rotation: a generalisable analytical framework. Environmental and Resource Economics, DOI: 10.1007/s10640-016-0077-4, 2016.

O. Musshof and S. Maart-Noelck. An experimental analysis of the behavior of forestry decision-makers - the example of timing in sales decisions. Forest Policy and Economics, 41:31-39, 2014.

B. Naslund. Optimal rotation and thinning. Forest Science, 15(4):446-451, 1969.

D.W. Ohlson, T.M. Berry, B.A. Gray, B.A. Blackwell, and B.C. Hawkes. Multi-attribute evaluation of landscape-level fuel management to reduce wildfire risk. Forest Policy and Economics, 8:824-837, 2006.

M. Ollikainen. A mean-variance approach to short-term timber selling and forest taxation under multiple sources of uncertainty. Canadian Journal of Forest Research, 20:1823-1829, 1993. 
A. Pinheiro and N. Ribeiro. Forest property insurance : an application to portuguese woodlands. International Journal of Sustainable Society, 5(3):284-295, 2013.

C. Price. When and to what extent do risk premia work? cases of threat and optimal rotation. Journal of Forest Economics, 17:53-66, 2011.

T. Pukkala and J. Kangas. A method for integrating risk and attitude toward risk into forest planning. Forest Science, 42(2):198-205, 1996.

H. Rakotoarison and P. Loisel. The faustmann model under storm risk and price uncertainty: A case study of european beech in northwestern france. Forest Policy and Economics, 81:30-37, 2017.

W.J. Reed. The effects of the risk of fire on the optimal rotation of a forest. Journal of Environmental Economics and Management, 11(2):180-190, 1984.

J.P. Roise. A nonlinear programming approach to stand optimization. Forest Science, 32(3):735-748, 1986.

P. Sauter, O. Musshoff, B. Mohring, and S. Wilhelm. Faustmann vs. real options theory - an experimental investigation of foresters' harvesting decisions. Journal of Forest Economics, 24:1-20, 2016.

M.J. Schelhaas, G.J. Nabuurs, and A. Schuck. Natural disturbances in the european forests in the 19th and 20th centuries. Global Change Biology, 9:1620-1633, 2003.

M. Schmidt, M. Hanewinkel, G. Kandler, E.Kublin, and U. Kohnle. An inventory-based approach for modeling single-tree storm damage - experiences with the winter storm of 1999 in southwestern germany. Canadian Journal of Forest Research, 40:1636-1652, 2010.

G.F. Schreuder. The simultaneous determination of optimal thinning schedule and rotation for an evenaged forest. Forest Science, 17(3):333-339, 1971.

D.L. Spittelhouse and R.B. Stewart. Adaptation to climate change in forest management. BC Journal of Ecosystems and Management, 4:1-11, 2003.

R. Taylor and J. Forston. Optimum plantation planting density and rotation age based on financial risk and return. Forest Science, 37(3):886-902, 1991. 
L. Valsta. A scenario approach to stochastic anticipatory optimization in stand management. Forest Science, 38:430-447, 1992.

R. Yin and D.H. Newman. The effect of catastrophic risk on forest investment decisions. Journal of Environmental Economics and Management, 31:186-197, 1996. 


\section{A The Faustmann Value}

As we assume that the storm occurs independently of one another and randomly in time, we deduce the following expression for the land value:

$$
J_{F}=E\left[\sum_{i=1}^{\infty} e^{-\delta\left(\tau_{1}+\tau_{2}+\ldots+\tau_{i}\right)} \mathcal{Y}_{i}\right]=\sum_{i=1}^{\infty} \prod_{j=1}^{i-1} E\left[e^{-\delta \tau_{j}}\right] . E\left[e^{-\delta \tau_{i}} \mathcal{Y}_{i}\right]=\frac{\left[e^{-\delta \tau} \mathcal{Y}\right]}{1-E\left[e^{-\delta \tau}\right]}
$$

From the definition of $\tau$ we deduce the expectation $E\left[e^{-\delta \tau}\right]$ :

$$
E\left[e^{-\delta \tau}\right]=\int_{t_{L}}^{T} e^{-\delta \tau} d F\left(\tau-t_{L}\right)+e^{-\delta T}\left(1-F\left(T-t_{L}\right)\right)=\frac{\lambda+\delta e^{-(\delta+\lambda)\left(T-t_{L}\right)}}{\delta+\lambda} e^{-\delta t_{L}}
$$

We deduce the expected net economic return $E\left[e^{-\delta \tau} \mathcal{Y}\right]$ actualized at initial time:

$$
\begin{aligned}
& \frac{1-e^{-\delta \underline{t}}}{\delta} u(-\mathcal{P})+\frac{e^{-\delta \underline{t}}-e^{-\delta t_{L}}}{\delta} u(h-\mathcal{P})+\frac{e^{-\delta t_{L}}-e^{(\delta+\lambda) T-\lambda t_{L}}}{\delta+\lambda} u(h-\mathcal{P}) \\
& +\int_{t_{L}}^{T}\left(E\left[u\left(V_{1}(\theta, \tau)+\mathcal{I}\left(\theta_{\tau}, \tau\right)-c_{1}-C_{n}\left(\theta_{\tau}, \tau\right)\right)\right]\right) e^{-\delta \tau} d F\left(\tau-t_{L}\right) \\
& +u\left(V(T)-c_{1}\right) e^{-\delta T}\left(1-F\left(T-t_{L}\right)\right)
\end{aligned}
$$

and hence the result.

\section{B Proof of Proposition 1}

To lighten the presentation, in some calculus, we omit the $\lambda$ dependency in functions $a_{1}, b$ and denote $a_{T}\left(\right.$ resp. $b_{T}$ ) the partial derivative of $a_{1}$ (resp. $b$ ) with respect to $T$.

From (1), differentiating $J_{F}$ with respect to the rotation age $T$ gives the following first-order condition:

$$
J_{T}=\left[\frac{W_{F}(0, T)+\frac{a_{1}(T)}{\delta}\left(\left(h u_{-}\right) I_{h<\mathcal{P}}+\left(h u_{+}+\mathcal{P}\left(u_{-}-u_{+}\right)\right) I_{h>\mathcal{P}}\right)}{b(T)}\right]_{T}=0
$$

We consider the case $h>\mathcal{P}$ (the other case is simpler). From the first-order condition $J_{T}=0$ we 
deduce:

$$
W_{F}(0, T)_{T} b(T)-W_{F}(0, T) b_{T}(T)+\left(a_{T}(T) b(T)-a_{1}(T) b_{T}(T)\right) \frac{h u_{+}+\mathcal{P}\left(u_{-}-u_{+}\right)}{\delta}=0
$$

Differentiating $J_{T}=0$ with respect to $\mathcal{P}$ yields: $J_{T T} T_{\mathcal{P}}+J_{T \mathcal{P}}=0$. From $J_{T T}<0, T_{\mathcal{P}}$ and $J_{T \mathcal{P}}$ have the same sign. $J_{T \mathcal{P}}$ is proportional (with the same sign) to the sum of:

$$
A_{\mathcal{P}}=W_{F}(0, T)_{T \mathcal{P}} b(T)-W_{F}(0, T)_{\mathcal{P}} b_{T}(T) \text { and }\left(a_{T}(T) b(T)-a_{1}(T) b_{T}(T)\right)\left(u_{-}-u_{+}\right)
$$

The difference $a_{T}(T) b(T)-a_{1}(T) b_{T}(T)$ is positive. Concerning $A_{\mathcal{P}}$ :

$$
\begin{aligned}
W_{F}(0, T)_{\mathcal{P}} & =\lambda \frac{u_{+}}{\bar{P}} \int_{t_{L}}^{T}(1-\alpha(\tau)) V(\tau) e^{(\lambda+\delta)(T-\tau)} d \tau \\
W_{F}(0, T)_{T \mathcal{P}} & =\lambda \frac{u_{+}}{\bar{P}}(1-\alpha(T)) V(T)+(\lambda+\delta) W_{F}(0, T)_{\mathcal{P}}
\end{aligned}
$$

From $b_{T}(T)=\delta+(\delta+\lambda) b(T)$ we deduce:

$$
\begin{aligned}
A_{\mathcal{P}} & =\lambda \frac{u_{+}}{\bar{P}}(1-\alpha(T)) V(T) b(T)-\delta W_{F}(0, T)_{\mathcal{P}} \\
& =\lambda \frac{u_{+}}{\bar{P}}\left[(1-\alpha(T)) V(T) b(T)-\delta \int_{t_{L}}^{T}(1-\alpha(\tau)) V(\tau) e^{(\lambda+\delta)(T-\tau)} d \tau\right]
\end{aligned}
$$

Let $\gamma(t)=\lambda \frac{u_{+}}{\bar{P}}(1-\alpha(t)) V(t) b(t)$ then:

$$
A_{\mathcal{P}}=\gamma(T) b(T)-\delta \int_{t_{L}}^{T} \gamma(\tau) e^{(\lambda+\delta)(T-\tau)} d \tau
$$

Moreover, studiing the behavior of $A_{\mathcal{P}}(t)=\gamma(t) b(t)-\delta \int_{t_{L}}^{t} \gamma(\tau) e^{(\lambda+\delta)(t-\tau)} d \tau$, then:

$$
\begin{aligned}
A_{\mathcal{P}}^{\prime}(t) & =\gamma^{\prime}(t) b(t)+\gamma(t) b_{T}(t)-\delta \gamma(t)-(\lambda+\delta)\left(\gamma(t) b(t)-A_{\mathcal{P}}(t)\right) \\
& =\gamma^{\prime}(t) b(t)+(\lambda+\delta) A_{\mathcal{P}}(t)
\end{aligned}
$$

From $\alpha^{\prime}(t)<0$ we deduce $\gamma^{\prime}(t)>0$, moreover from $A_{\mathcal{P}}(0)=0$ we deduce that $A_{\mathcal{P}}(T)>0$. 


\section{Proof of Proposition 2}

We consider the derivative of the Faustmann Value $J_{F}$ with respect to insurance premium $\mathcal{P}$ :

$$
\begin{aligned}
\frac{\partial J_{F}}{\partial \mathcal{P}} & =-\frac{a_{0}(T) u^{\prime}(-\mathcal{P})+a_{1}(T) u^{\prime}(h-\mathcal{P})}{\delta b(T)} \\
& +\frac{1}{\left(1+l_{f}\right)(1+m) \delta_{A}} \frac{b_{A}(T)}{b(T)} \frac{\int_{t_{L}}^{T} E\left[u^{\prime}\left(V_{1}(\theta, \tau)+\mathcal{I}\left(\theta_{\tau}, \tau\right)-c_{1}-C_{n}\left(\theta_{\tau}, \tau\right)\right) L(\theta, \tau)\right] e^{(\lambda+\delta)(T-\tau)} d \tau}{\int_{t_{L}}^{T} E\left[L\left(\theta_{\tau}, \tau\right)\right] e^{\left(\lambda+\delta_{A}\right)(T-\tau)} d \tau}
\end{aligned}
$$

(i) From the concavity of the utility $u$, and using $-\mathcal{P}<h-\mathcal{P}<V_{1}(\theta, \tau)+\mathcal{I}\left(\theta_{\tau}, \tau\right)-c_{1}$ then:

$$
\frac{\partial J_{F}}{\partial \mathcal{P}}<\frac{1}{\delta}\left(-1+\frac{1}{\left(1+l_{f}\right)(1+m)} \frac{\delta}{\delta_{A}} \frac{b_{A}(T)}{b(T)} \frac{\int_{t_{L}}^{T} E\left[L\left(\theta_{\tau}, \tau\right)\right] e^{(\lambda+\delta)(T-\tau)} d \tau}{\int_{t_{L}}^{T} E\left[L\left(\theta_{\tau}, \tau\right)\right] e^{\left(\lambda+\delta_{A}\right)(T-\tau)} d \tau}\right) u^{\prime}(h-\mathcal{P})
$$

From $\delta_{A}=\delta$ then $b_{A}=b$ and $\frac{\partial J_{F}}{\partial \mathcal{P}}<\frac{1}{\delta}\left(-1+\frac{1}{\left(1+l_{f}\right)(1+m)}\right) u^{\prime}(h-\mathcal{P})<0$, hence the result.

(ii) $\frac{\partial J_{F}}{\partial \mathcal{P}}$ is proportional to:

$$
\begin{aligned}
& -\left(a_{0}(T) u^{\prime}(-\mathcal{P})+a_{1}(T) u^{\prime}(h-\mathcal{P})\right) \frac{\delta_{A}}{b_{A}(T)} \int_{t_{L}}^{T} E\left[L\left(\theta_{\tau}, \tau\right)\right] e^{\left(\lambda+\delta_{A}\right)(T-\tau)} d \tau \\
& +\frac{1}{\left(1+l_{f}\right)(1+m)} \delta \int_{t_{L}}^{T} E\left[u^{\prime}\left(V_{1}(\theta, \tau)+\mathcal{I}\left(\theta_{\tau}, \tau\right)-c_{1}-C_{n}\left(\theta_{\tau}, \tau\right)\right) L(\theta, \tau)\right] e^{(\lambda+\delta)(T-\tau)} d \tau
\end{aligned}
$$

If the forest owner's discount rate and the insurer's discount rate are sufficiently unequal then $\frac{\partial J_{F}}{\partial \mathcal{P}}>0$ for sufficiently large value of $\delta$, hence $\frac{\partial J_{F}}{\partial \mathcal{P}}$ is equal to zero for smaller $\delta$ and we deduce the existence of a non trivial solution $\mathcal{P}_{*}(T)>0$. 


\section{Proof of Proposition 3}

If $\delta_{A}=\delta$ then $b_{A}=b$ and:

$$
\begin{aligned}
\frac{\partial J_{F}}{\partial \mathcal{P}}= & -\frac{a_{0}(T) u^{\prime}(-\mathcal{P})+a_{1}(T) u^{\prime}(h-\mathcal{P})}{\delta b(T)} \\
& +\frac{\int_{t_{L}}^{T} E\left[u^{\prime}\left(V_{1}(\theta, \tau)+\mathcal{I}\left(\theta_{\tau}, \tau\right)-c_{1}-C_{n}\left(\theta_{\tau}, \tau\right)\right) L(\theta, \tau)\right] e^{(\lambda+\delta)(T-\tau)} d \tau}{\delta(1-\gamma)\left(1+l_{f}\right)(1+m) \int_{t_{L}}^{T} E\left[L\left(\theta_{\tau}, \tau\right)\right] e^{(\lambda+\delta)(T-\tau)} d \tau}
\end{aligned}
$$

$\frac{\partial J_{F}}{\partial \mathcal{P}}$ is positive for sufficiently large value $\gamma$ and is negative for $\gamma=0$. Hence we deduce that for intermediate $\gamma, \frac{\partial J_{F}}{\partial \mathcal{P}}$ may be equal to 0 , hence a non null premium $\mathcal{P}$ will be optimal. 